\title{
Tuberculosis in patients with systemic lupus erythematosus
}

\author{
P. H. FENG AND T. H. TAN \\ From the Department of Medicine IV, Tan Tock Seng Hospital, Singapore
}

SUMMARY Tuberculosis associated with systemic lupus erythematosus (SLE) was studied in a cohort of 311 patients seen between 1963 to 1979. There were 16 such patients, giving rise to a prevalence rate of $5 \%$. The characteristics of SLE-associated tuberculosis include a high incidence of miliary and far-advanced pulmonary disease, delay in establishing diagnosis, especially the extrapulmonary form, and tendency to attribute symptoms like fever, malaise, and weight loss to the lupus process. Treatment was successful in 9 patients. Of the 7 deaths 5 were attributed directly to the mycobacterial infection and 2 to complications of SLE.

In spite of an increased incidence of infection an association between tuberculosis and systemic lupus erythematosus (SLE) has been noied only infrequently..$^{1-3}$ The present report describes a systematic review of tuberculous infection in a cohort of 311 patients with SLE undergoing treatment with various immunosuppressive drugs over a period of 16 years from 1963 to 1979.

\section{Materials and methods}

\section{PATIENTS}

We reviewed the records of 311 patients diagnosed as SLE from 1963 to 1979 . All these patients fulfilled at least 4 of the criteria laid down by the American Rheumatism Association. ${ }^{4}$ The diagnosis of tuberculosis was made on radiological, bacteriological, and histological grounds.

\section{EVALUATION OF DISEASE ACTIVITY}

Clearly there are problems in defining disease activity in such a pleomorphic condition as SLE. Since renal status is one of the basic determinants of prognosis, we have adopted the system of Cameron et al. ${ }^{5}$ (Table 1) to score disease activity arbitrarily. An added advantage of this system is that some weight is given to nonrenal manifestations as well as renal. Disease activity was expressed on a 7-point scale. A score of 1 or 2 was designated as mild disease and a score of 3-7 as moderate or severe disease.

Accepted for publication 23 February 1981.

Correspondence to Dr P. H. Feng, Department of Medicine IV, Tan Tock Seng Hospital, Moulmein Road, Singapore 1130.
Table 1 Assessment of disease activity

\begin{tabular}{ll}
\hline & Score \\
\hline Renal manifestations: & \\
Falling GFR/rising serum creatinine & 2 \\
Proteinuria present & 1 \\
Proteinuria but in excess $4 \mathrm{~g} /$ day or serum albumin & 2 \\
$\quad<2.5 \mathrm{~g} / \mathrm{dl}(25 \mathrm{~g} / 1)$ & 1 \\
Sustained diastolic hypertension & 1 \\
Extrarenal manifestations: & 2 \\
$\quad$ Mild & 2 \\
\hline
\end{tabular}

* Maximum possible score 7.

From Cameron et al. 5

GFR = glomerular filtration rate.

\section{THER A P Y}

Treatment of SLE was along standard lines. All patients received steroids initially at a dosage of prednisolone $60-20 \mathrm{mg}$ a day depending on disease activity and specific organ involvement. The dosage was reduced gradually once the disease came under control. Cyclophosphamide was added at a dose of $1.5 \mathrm{mg} / \mathrm{kg}$ body weight in steroid failure or in those who developed severe steroid side effects. At the time of diagnosis of tuberculosis 15 of the patients were on prednisolone varying from $45 \mathrm{mg}$ to $5 \mathrm{mg}$ daily (mean daily dose $26 \mathrm{mg}$ ). Two of the patients received cyclophosphamide as well. One patient (case 7) was off drugs, as she was in remission.

For tuberculosis 8 patients received a combination of streptomycin ( $1 \mathrm{~g}$ daily), ethambutol $(25 \mathrm{mg} / \mathrm{kg}$ body weight per day for first 8 weeks followed by $15 \mathrm{mg} / \mathrm{kg}$ body weight per day), and isoniazid ( $300 \mathrm{mg} / \mathrm{day})$. Six patients received a combination 
of streptomycin, para-aminosalicylic acid (10 g/day) and isoniazid. Two patients received a combination of rifampin ( $450 \mathrm{mg} /$ day), ethambutol, and isoniazid. One patient developed skin sensitivity to streptomycin, and she was switched over to a combination of kanamycin ( $1 \mathrm{~g} 4$ times a week), pyrazinamide (20-35 mg/kg), and rifampin. Case $16 \mathrm{did}$ not respond to a combination of streptomycin, paraaminosalicylic and isoniazid and was changed over to rifampin, pyrazinamide, ethambutol, and ethionamide (250 $\mathrm{mg}$ thrice daily).

\section{Results}

CLINICAL FEATURES OF SLE

Detailed clinical features are presented in Table 2. All 16 patients had cutaneous and musculoskeletal involvement in the form of rash and arthritis. Nine patients had renal disease in the form of haematuria, nephrotic syndrome, and raised blood urea nitrogen or creatinine. Other systemic involvement included neuropsychiatric, respiratory, cardiac, haematological, or gastrointestinal manifestations.

\section{SPECTRUM OF TUBERCULOSIS}

This is shown in Table 3. Fever, cough, sputum, haemoptysis, dyspnoea, and weight loss were common in these patients but not invariably present. Some of these symptoms were initially attributed to the SLE itself.

Seven of the patients ( $44 \%$ ) developed tuberculosis within the first 12 months of therapy for SLE. Nine patients $(57 \%)$ developed tuberculosis within the first 2 years of therapy. With the exception of 1 case (no. 7) who had haemoptysis 2 years prior to development of active radiological lesion, diagnosis of tuberculosis was established within 3 months of onset of symptoms. This was done with radiology and/or sputum examination and culture in 14 cases. In case 5 the diagnosis was reached only at laparotomy, and in case 15 lymph node biopsy confirmed the diagnosis. In case 6 tuberculous osteomyelitis was confirmed by exploration of the left hip, though the chest radiograph also revealed a soft opacity suggestive of minimal tuberculosis.

\section{RESULTS OF THERAPY}

All patients were started on antituberculous therapy immediately on confirmation of diagnosis. All who completed chemotherapy had shown both radiological clearing and bacteriological conversion. Side effects of chemotherapy were infrequent and necessitated change of drug in only 1 patient (case 9). Of the 16 patients 7 died, giving a total mortality of $44 \%$. Two patients died as result of complications of SLE, 1 of uraemia, and 1 of infection. Five patients $(31 \%)$ died directly as result of tuberculosis. These patients had either very advanced cavitating pulmonary disease or miliary spread. Duration of treatment for this group varied from less than 1 month to 12 months.

\section{EFFECT OF DISEASE ACTIVITY AND STEROID} THERA PY

The number of tuberculous patients in relation to disease activity and steroid therapy is shown in Table 4. Eleven patients developed tuberculosis while their SLE was moderately severe or severe

Table 2 Profile of patient population

\begin{tabular}{|c|c|c|c|c|c|c|c|c|}
\hline \multirow[t]{2}{*}{ Case } & \multirow[t]{2}{*}{ Age } & \multirow[t]{2}{*}{ Sex } & \multicolumn{5}{|c|}{ SLE systemic manifestations } & \multirow[t]{2}{*}{ Initial therapy (mg/day) } \\
\hline & & & Musculoskeletal & Renal & Neuropsychiatric & Raised BP & Others & \\
\hline 1 & 36 & $\mathbf{F}$ & + & + & + & + & Thrombocytopenia, GIT & P 60 \\
\hline 2 & 27 & $\mathbf{F}$ & + & & & & $\begin{array}{l}\text { Pulmonary hypertension, } \\
\text { heart block }\end{array}$ & P 60 \\
\hline 3 & 38 & $\mathbf{F}$ & + & & & & & P 15 \\
\hline 4 & 54 & $\mathbf{M}$ & + & + & & + & Thrombocytopenia & P 45 \\
\hline 5 & 23 & $\mathbf{F}$ & + & + & & & & $\begin{array}{l}\text { P } 45 \\
\text { E } 100\end{array}$ \\
\hline 6 & 25 & $\mathbf{F}$ & + & & & & & P 20 \\
\hline 7 & 30 & $\mathbf{F}$ & + & + & & & & P 30 \\
\hline 8 & 26 & $\mathbf{F}$ & + & . & & + & Lymphadenopathy & P 40 \\
\hline 9 & 38 & $\mathbf{F}$ & + & + & + & + & & P 45 \\
\hline 10 & 21 & $\mathbf{F}$ & + & + & + & & & $\begin{array}{l}\text { P } 40 \\
\text { E } 100\end{array}$ \\
\hline 11 & 17 & $\mathbf{F}$ & + & + & & & Thrombocytopenia, ascites & P 30 \\
\hline 12 & 28 & $\mathbf{F}$ & + & & & & & P 30 \\
\hline 13 & 63 & $\mathbf{F}$ & + & + & & & Lung fibrosis & \\
\hline 14 & 37 & $\mathbf{F}$ & + & & & & & P 30 \\
\hline 15 & 20 & $\mathbf{F}$ & + & + & & & & $\begin{array}{l}\text { P } 40 \\
\text { E } 100\end{array}$ \\
\hline 16 & 55 & $\mathbf{F}$ & + & & & & & P 30 \\
\hline
\end{tabular}

$\mathbf{P}=$ prednisolone. $\quad \mathbf{E}=$ cyclophosphamide (Endoxan). $\quad \mathrm{BP}=$ blood pressure. $\quad$ GIT = gastrointestinal tract. 
Table 3 Spectrum of tuberculosis

\begin{tabular}{|c|c|c|c|c|c|c|}
\hline Case & $\begin{array}{l}\text { Clinical } \\
\text { symptoms }\end{array}$ & $\begin{array}{l}\text { Predominent site } \\
\text { of infection }\end{array}$ & $\begin{array}{l}\text { Positive } \\
\text { diagnostic procedures }\end{array}$ & $\begin{array}{l}\text { Therapy at } \\
\text { time of diagnosis } \\
\text { ( } m g / \text { day) }\end{array}$ & $\begin{array}{l}\text { Interval } \\
S L E \rightarrow T B \\
\text { (months) }\end{array}$ & $\begin{array}{l}\text { Delay in } \\
\text { establishing } \\
\text { diagnosis } \\
\text { (months) }\end{array}$ \\
\hline 1 & $\begin{array}{l}\text { Fever, cough, } \\
\text { weight loss }\end{array}$ & Lung (far advanced) & $X$-ray, sputum & P 40 & 6 & 3 \\
\hline 2 & Cough & Lung (moderately advanced) & $X$-ray, sputum & P 40 & 3 & 1 \\
\hline 3 & Cough, weight loss & Lung (moderately advanced) & $X$-ray, sputum & P 7.5 & 72 & 1 \\
\hline 5 & $\begin{array}{l}\text { Fever, chills, } \\
\text { ascites, LIF mass }\end{array}$ & Abdomen & Laparotomy & P 40 & 36 & 3 \\
\hline 6 & $\begin{array}{l}\text { Pain and swelling } \\
\text { left hip }\end{array}$ & $\begin{array}{l}\text { Lung (minimal) } \\
\text { TB hip }\end{array}$ & $\begin{array}{c}X \text {-ray, surgical } \\
\text { exploration }\end{array}$ & P 10 & 12 & 2 \\
\hline 7 & Haemoptysis & Lung (moderately advanced) & $X$-ray, sputum & - & 124 & 24 \\
\hline 8 & $\begin{array}{l}\text { Fever, cough, } \\
\text { dyspnoea }\end{array}$ & Lung (miliary) & $X$-ray, sputum & P 45 & 30 & 1 \\
\hline 9 & Fever, chills & Lung (miliary) & $X$-ray, sputum & P 45 & 84 & 2 \\
\hline 10 & Fever, cough & Lung (far advanced) & $X$-ray, sputum & P $20+E$ & 44 & 1 \\
\hline 12 & Fever & Lung (miliary) & $X$-ray, sputum & $\mathbf{P} 30+\mathbf{E}$ & 9 & 2 \\
\hline 13 & Fever, chest pain & Lung (miliary) & $X$-ray & P 30 & 18 & 1 \\
\hline 14 & Fever, cough & Lung (miliary) & $X$-ray, sputum & P 15 & 7 & 1 \\
\hline 15 & $\begin{array}{l}\text { Mass right } \\
\text { clavicular fossa }\end{array}$ & Lymph node & Biopsy & P 15 & 33 & 2 \\
\hline 16 & Cough & Lung (far advanced) & $X$-ray, sputum & P 30 & 17 & 1 \\
\hline
\end{tabular}

$\mathbf{P}=$ prednisolone. $\quad \mathrm{E}=$ cyclophosphamide (Endoxan). $\quad$ LIF $=$ left iliac fossa.

Table 4 Result of therapy

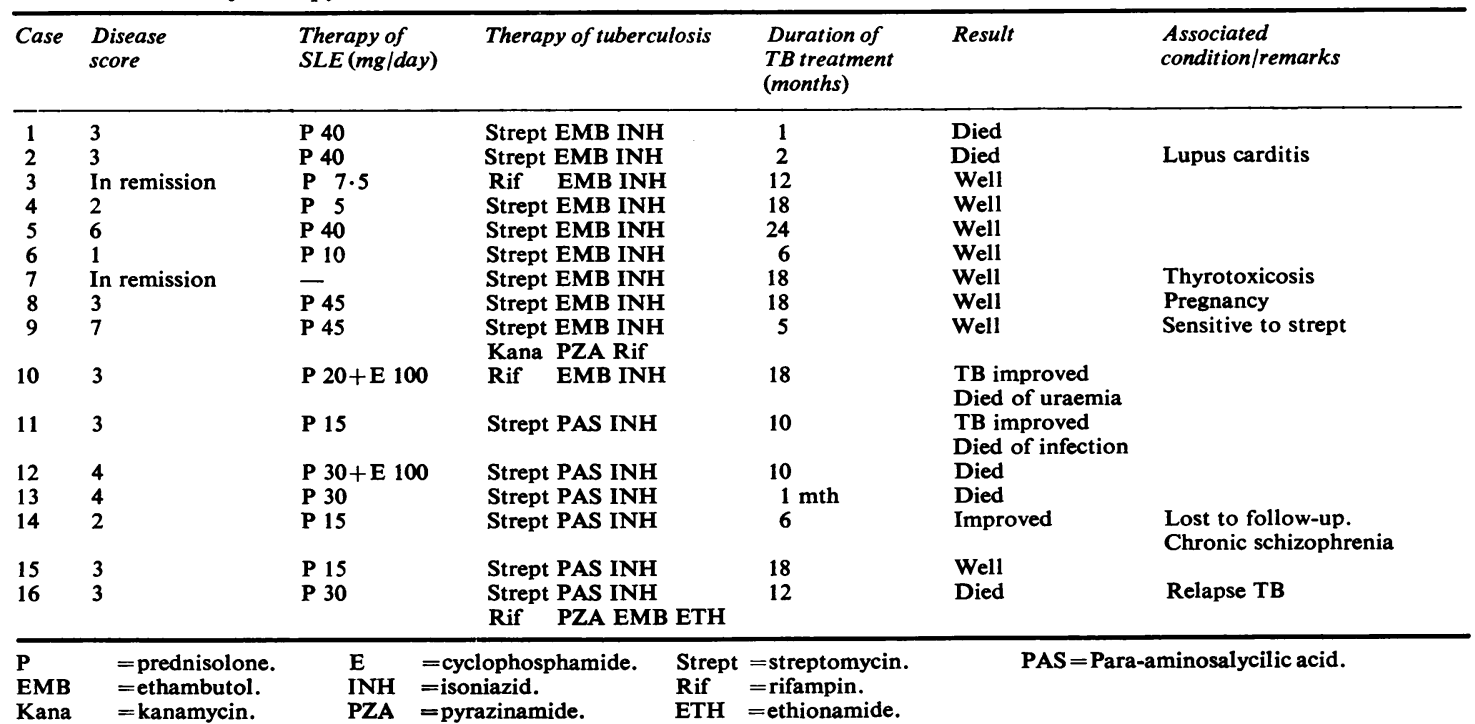

(scale 3-7). Their steroid dosage varied from 15 to $45 \mathrm{mg}$ per day (mean $32 \mathrm{mg}$ ). Two of them were on cyclophosphamide $100 \mathrm{mg} /$ day as well. The type of tuberculosis in these 11 patients included 4 miliary, 4 pulmonary ( 3 far advanced and 1 moderately advanced), 1 abdominal, 1 lymphadenitis, and 1 pleural effusion. All the 7 deaths occurred in this group. The spectrum of tuberculosis in patients with mild SLE (on a scale of 1-2) or in remission were miliary in 1 , pulmonary in 4 ( 1 minimal with TB osteomyelitis and 3 moderately advanced). There was no far advanced or cavitating disease in this group. Prednisolone dosage in this group ranged from 5 to $15 \mathrm{mg}$ per day.

\section{Discussion}

The high incidence of serious infections is one of the 
most disturbing problems in the management of patients with SLE. Besides immunosuppressive therapy several immunological abnormalities appear to contribute to the pathogenesis. ${ }^{6-9}$ Hence such patients are at an increased risk of viral, mycotic, and other opportunistic infections. ${ }^{10-13}$ The risk of specific tuberculous infection in immunosuppressed patients, however, has not been emphasised until very recently. Millar and Horne ${ }^{14}$ reported 11 patients who developed tuberculosis while on longterm immunosuppressive therapy. Three of the patients died as a result of the disease. Sahn and Lakshminarayan ${ }^{15}$ described 13 cases of tuberculosis in patients on corticosteroid therapy. All but one of them had an underlying condition associated with reduced immunity. Recently dialysis-associated tuberculosis has attracted considerable attention. Sasaki et al. ${ }^{16}$ reported 12 tuberculosis patients out of 367 patients on maintenance haemodialysis in a survey from January 1967 to December 1976, giving an incidence of $3.3 \%$. This was 6-16 times greater than that in the general population of Japan according to yearly statistics. Roughly similar results were obtained by Lundin et al. ${ }^{17}$ and Rutsky and Rostand. ${ }^{18}$

On the other hand only sporadic reports of tuberculous infection in SLE patients have appeared. The general impression was that such an association was uncommon even in those treated with steroids and immunosuppressive drugs. We are unaware of any data analysing the relationship of SLE and tuberculosis. The relatively high prevalence in our patients suggests that physicians taking care of such patients should be aware of this potential hazard. This is especially true in geographical regions like Singapore where the incidence of new cases per year is around 3000 and there are probably twice the number of undiagnosed cases. ${ }^{19}$ In spite of this heightened awareness the average interval between presentation and diagnosis was 1.5 months (range 1-3 months apart from case 7). In general, it took a longer period to establish definitive diagnosis in cases of extrapulmonary infection. This is due to the need for tissue examination. Our experience suggests that any prolonged febrile episodes, cough, sputum, dyspnoea, and weight loss should be viewed with suspicion. Unexplained pulmonary infiltrates, lymphadenopathy, pleural effusion, and ascites should be evaluated aggressively for active tuberculosis and not be attributed to the original disease. Severity of SLE and steroid dosage correlated positively with severity of tuberculosis and mortality. In individual patients with a clinical course compatible with tuberculosis, though lacking in histological or laboratory confirmation, a judicious trial of anti- mycobacterial drug therapy is probably indicated. Lastly a programme of assessment as recommended by Millar and Horne ${ }^{14}$ for immunosuppressed patients at risk of developing tuberculosis is warranted if we are further to reduce the mortality and morbidity in this group of patients.

\section{References}

1 Staples P J, Gerding D N, Decker J L, Gordon R S. Incidence of infection in systemic lupus erythematosus. Arthritis Rheum 1974; 17: 1-10.

2 Lee P, Urowitz M B, Bookman A A M, et al. Systemic lupus erythematosus: a review of 110 cases with reference to nephritis, the nervous system, infections, aseptic necrosis and prognosis. $Q \mathrm{~J}$. Med 1977; 46: 1-32.

3 Ginzler E, Diamond H, Kaplan D, Weiner M, Schlesmger M, Seleznick M. Computer analysis of factors influencing frequency of infection in systemic lupus erythematosus. Arthritis Rheum 1978; 21 : 37-44.

4 Cohen A S, Reynolds W E, Franklin E C, et al. Preliminary criteria for the classification of systemic lupus erythematosus. Bull Rheum Dis 1971 ; 21 : 643-8.

5 Cameron J S, Turner D R, Vosnides G, et al. The kidney in systemic lupus erythematosus. In: Becker $\mathrm{E} \mathrm{L}$, ed. Seminars in Nephrology. New York: John Wiley and Sons, 1977: 41-81.

6 Baum J, Ziff M. Decreased 19S antibody response to bacterial antigens in systemic lupus erythematosus. $J$ Clin Invest 1969; 48: 758-67.

7 Brandt L, Herberg H. Impaired phagocytosis by peripheral blood granulocytes in systemic lupus erythematosus. Scand J. Haematol 1969; 6: 348-53.

8 Rosenthal C J, Franklin E C. Deficiency of cell mediated immunity in active SLE: changing patterns after steroid therapy. Arthritis Rheum 1975; 18: 207-17.

9 Alvarez I, Vazquez J J, Fontan G, Gil A, Barbado J, Ojeda $J$ A. Neutrophil chemotaxis and serum chemotactic activity in systemic lupus erythematosus. Scand $J$ Rheumatol 1978; 7: 69-74.

10 Montsopoulos H M, Gallagher J D, Decker J L, Steinberg A D. Herpes zoster in patients with systemic lupus erythematosus. Arthritis Rheum 1978; 21 : 798-802.

11 Pillay V K G, Wilson D M, Ing T S, Kark R M. Fungus infection in steroid-treated systemic lupus erythematosus. JAMA 1968; 205: 261-5.

12 Khan M A, Sbar S. Cryptococcal meningitis in steroidtreated systemic lupus erythematosus. Postgrad Med J 1975; $51: 660-2$.

13 Gorevic P D, Katler E I, Agus B. Pulmonary nocardiosis. Occurrence in men with systemic lupus erythematosus. Arch Intern Med 1980; 140: 361-3.

14 Millar J W, Horne N W. Tuberculosis in immunosuppressed patients. Lancet 1979; i: 1176-8.

15 Sahn S A, Lakshminarayan S. Tuberculosis after corticosteroid therapy. Br J Dis Chest 1976; 70: 195-205.

16 Sasaki S, Akiba T, Suenaga M, et al. Ten years' survey of dialysis associated tuberculosis. Nephron 1979; 24: 141-5.

17 Lundin A P, Alder A J, Berlyne G M, Friedman E A. Tuberculosis in patients undergoing maintenance hemodialysis. Am J Med 1979; 67: 597-602.

18 Rutsky E A, Rostand S G. Mycobacteriosis in patients with chronic renal failure. Arch Intern Med 1980; 140: 57-61.

19 Singapore Tuberculosis Statistics. Singapore: Department of Tuberculosis Control, Tan Tock Seng Hospital, Ministry of Health, 1979. 